\title{
Frictional Behavior and Surface Failure of Human Enamel
}

\author{
J. M. POWERS, R. G. CRAIG, and K. C. LUDEMA
}

School of Dentistry, University of Michigan, Ann Arbor, Michigan 48104, USA, and College of Engineering, University of Michigan, Ann Arbor, Michigan

The frictional behavior and surface failure of human enamel under sliding in water was examined. A large plowing component of friction was observed. For normal loads of up to $1 \mathrm{~kg}$, ductile behavior of the wear scar was apparent. Intermittent cracks were observed that appeared to propagate around the enamel rods.

Historically, the study of the wear of hard dental tissues in modern man has been limited to clinical observation of physiologic and pathologic conditions that lead to wear, and to attempts to duplicate the effects of hygienic procedures such as the use of toothbrush and dentifrice on hard dental tissues in the laboratory. However, several fundamental investigations have been reported in which the wear of enamel and dentin under conditions of abrasion, ${ }^{1}$ and the damage done to enamel during preparative techniques such as grinding with high- or low-speed diamond stones or carbide burs, 2,3 were examined.

A different approach to characterizing wear has been to examine a material under conditions of single-pass sliding. Such an approach has proven successful in studying the effects of sliding direction and environment on the frictional behavior and surface failure of natural fluorapatite single crystals. 4

The purpose of the present study was to examine the frictional behavior and surface failure of human enamel and to determine the presence of a ductile-to-brittle transition (DBT) for human enamel.

This paper is based on a dissertation submitted in partial fulfilment of the requirements for the PhD degree in the Horace $H$. Rackham School of Graduate Studies at the University of Michigan, 1972

This study was supported, in part, by USPHS Training Grant DE-00181 from the National Institute of Dental Research, National Institutes of Health, Bethesda, Md.

Received for publication May 11, 1972.

\section{Materials and Methods}

The buccal-occlusal surfaces of 12 human, mandibular left third molars were scratched in a mesial-distal sliding direction as diagrammed in Figure 1. Ten parallel, onetraversal scratches were made on six of the specimens (E 13 to 18 ) by sliding under normal loads of 100 to $1,000 \mathrm{gm}$ in increments of $100 \mathrm{gm}$. On the six others (E 20 to 25), five parallel, one-traversal scratches were made by sliding under normal loads of 1 to $5 \mathrm{~kg}$ in increments of $1 \mathrm{~kg}$. All specimens were run in distilled water. The apparatus used for scratching the surface of a specimen and measuring the tangential force was described previously in detail. 4

Tangential force and track width data were collected for specimens E 13 to 18. For these and specimens E 20 to 25 , the failure classification of each scar was determined under optical magnification. ${ }^{a}$ The mechanism of surface failure was studied with a scanning electron microscope (SEM). ${ }^{b}$ The measured values of track width were compared qualitatively with values computed from an equation derived from a special case of Hertz's theory of contact between two elastic spheres. ${ }^{4}$

\section{Results}

Over the load range of 100 to $1,000 \mathrm{gm}$, measured track width values were considerably larger than those calculated from the Hertzian model (Fig 2) .c The values of the

\footnotetext{
a Aristophot, Ernst Leitz, Wetzlar, W Ger.

b JSM-U3, Japan Electron Optics Laboratories, Jap.

c In this calculation Poisson's ratio and Young's modulus for diamond were 0.30 and $9.48 \times 10^{4} \mathrm{~kg} / \mathrm{mm}^{2}$, respectively. 5 Poisson's ratio for enamel was chosen as 0.28. Two values of Young's modulus for enamel chosen to indicate a range of elastic behavior were $7.94 \times 10^{3} \mathrm{~kg} / \mathrm{mm}^{2}$ and $1.42 \times 10^{4} \mathrm{~kg} / \mathrm{mm}^{2}$. The lower value represents a modulus in compression measured for side enamel. ${ }^{-}$The higher value represents the modulus in the $[00017$ direction for a single crystal of hydroxyapatite as calculated by Katz and Ukraincik. ${ }^{7}$
} 

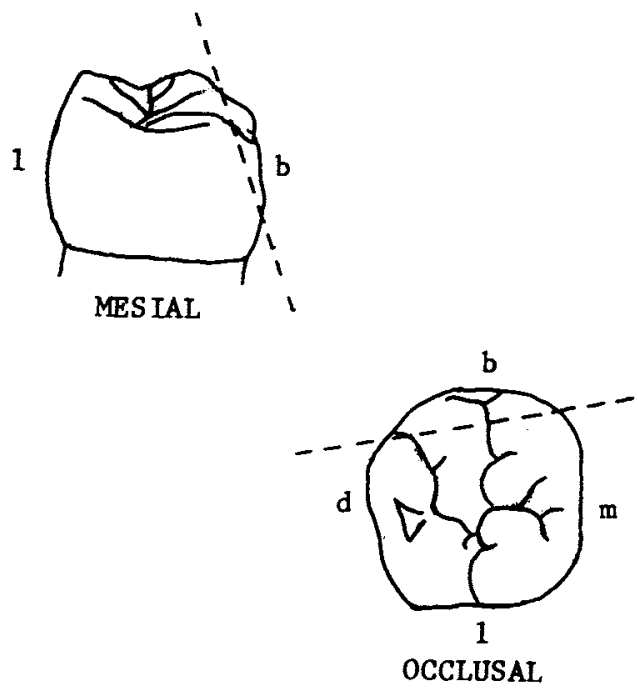

(c) PHASE 3

Fic 1.-Diagram of experimental procedure.

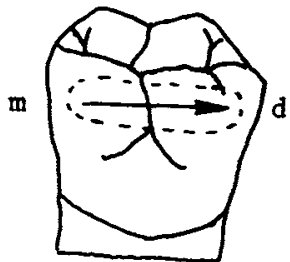

BUCCAL coefficient of friction $(\beta)$ as determined by regression analysis for these six crystals ( $E$ 13 to 18 ) were $0.389,0.393,0.326,0.323$, 0.373 , and 0.385 , respectively. The average standard error was 0.008 .

SEM photomicrographs are shown in Figure 3 for an enamel specimen (E 12) run under conditions of sliding similar to those described for specimens E 13 to 18. These photomicrographs represent observations typical for the enamel specimens examined in the load range of 100 to $1,000 \mathrm{gm}$. The surface failure shown in Figure 3, left, was characteristic of a Class I failure in enamel.

At loads greater than the normal load of $400 \mathrm{gm}$, tensile failure, as characterized by cracks at the edge of the wear scar, was observed for specimens E 13 to 18 . Tensile cracks were not regularly distributed along the wear scar, but were intermittent in occurrence. Such a crack is shown in Figure 3, right, for specimen E 12 at a normal load of $375 \mathrm{gm}$.

Photomicrographs taken on a metallograph are shown in Figures 4 and 5 for an enamel specimen (E 20) examined in the load range of 1 to $5 \mathrm{~kg}$. Figure 4 was taken slightly out of focus to enhance the contrast of the speci-

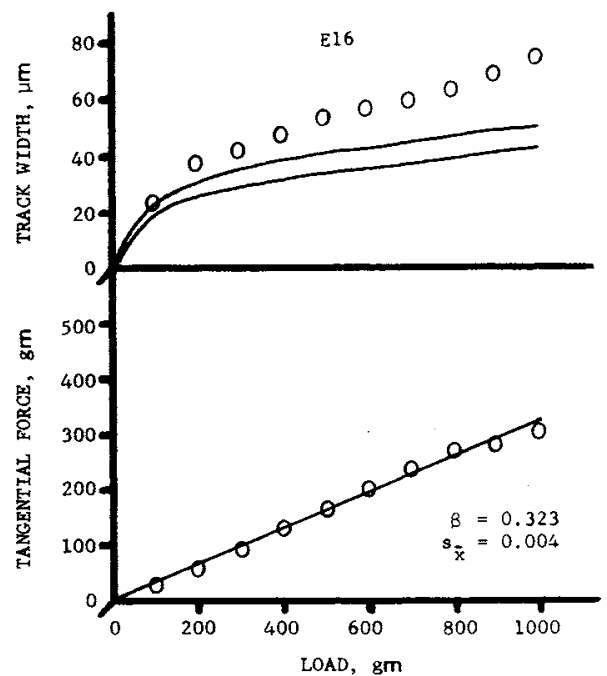

Fig 2.-Track width and tangential force load for specimen E 16 in water. Upper and lower curves, which represent track width as a function of load, were computed on basis of Hertzian equation of elasticity. Young's modulus for enamel was $7.94 \times 10^{3} \mathrm{~kg} / \mathrm{mm}^{2}$ for upper curve and $1.47 \times 10^{4} \mathrm{~kg} / \mathrm{mm}^{2}$ for the lower curve. 

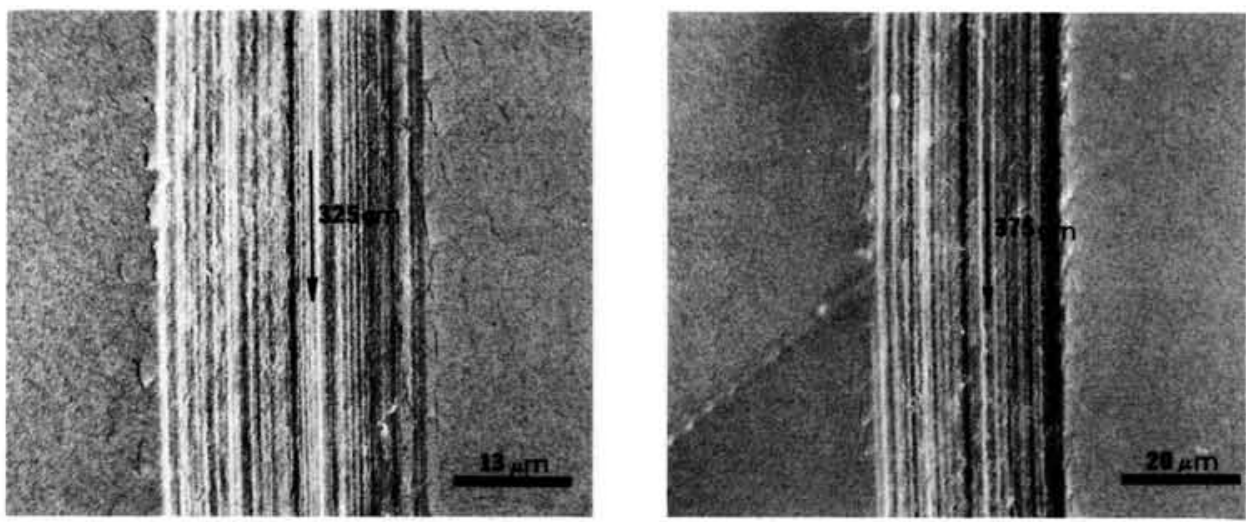

Fic 3.-Wear tracks on enamel for sliding in water.

men to show the Hunter-Schreger bands. ${ }^{\mathrm{d}}$ Several of the cracks emanating from the edges of the wear scars on this and other specimens appeared to follow the contour of these bands. Figure 5 exemplifies the type of surface damage observed for specimens of enamel run in this load range. Enamel rods that were difficult to see on polished but unscratched specimens were observed easily in immediate proximity to the wear scars (Fig

d Hunter-Schreger bands are optical effects that result from a change in direction of the enamel rods during formation.
5, left). Further from the scars, however, the rods were seen less easily. It was observed (Fig 5, right) that tensile cracks that occurred along the wear scars appeared to propagate between the enamel rods rather than through them. Figure 6 is a magnified view of the enamel rods that were observed near the wear scar shown in Figure 5, left. These rods were observed to a lesser extent near the wear tracks that occurred in the load range of 100 to $1,000 \mathrm{gm}$ (Fig 3). At loads greater than $3 \mathrm{~kg}$, for specimens E 20 to 25 , the slider broke through the polished enamel

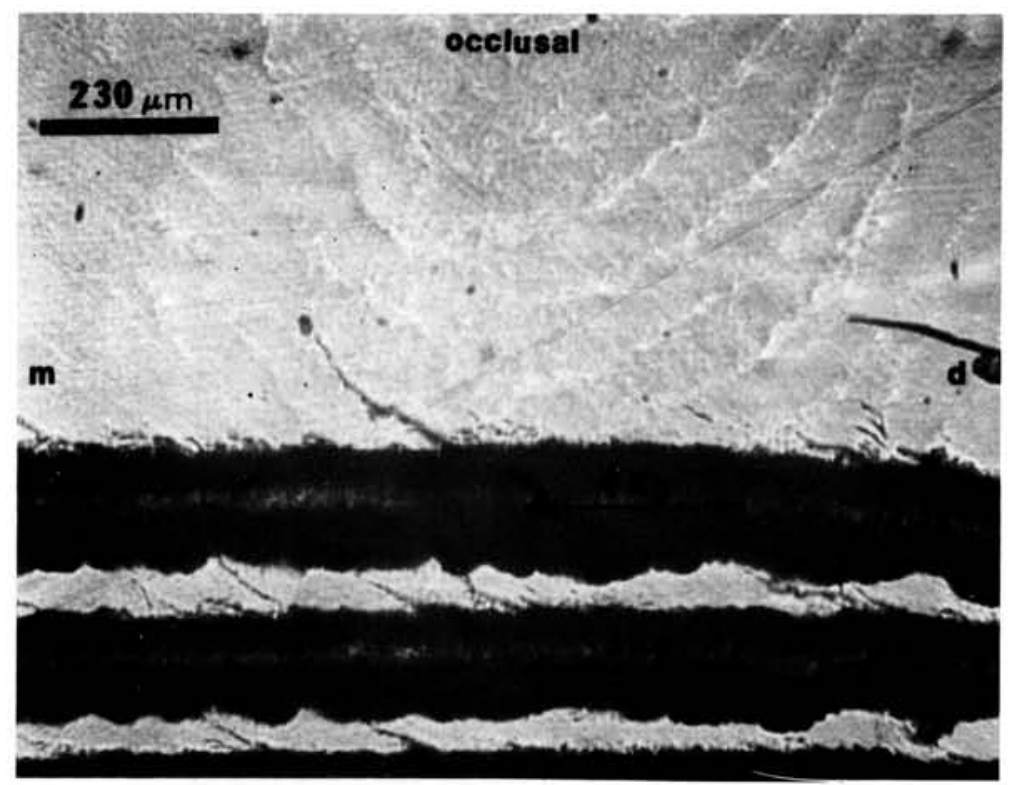

Fig 4.-Wear scars on enamel for sliding in water. 

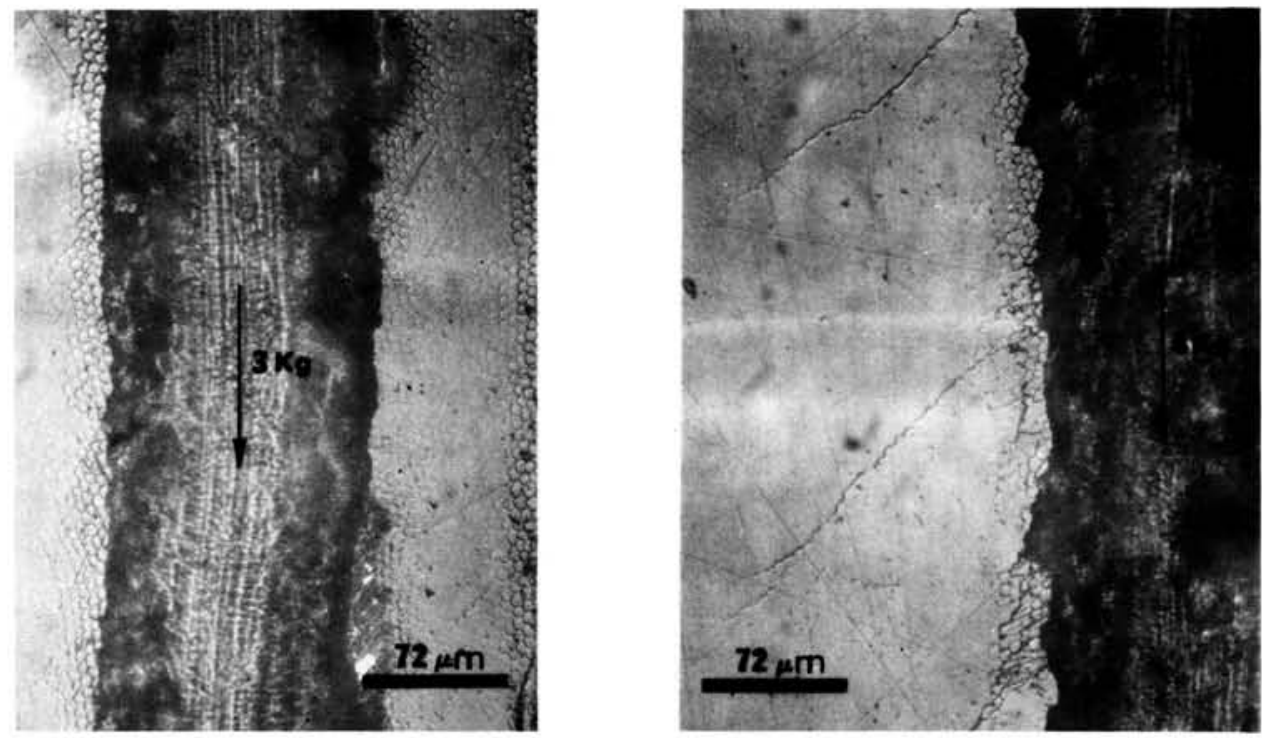

FIG 5.-Wear tracks on enamel for sliding in water.

surface. Such a failure is apparent in Figure 5. For this reason, meaningful values of tangential force and track width for specimens E 20 to 25 were difficult to measure.

\section{Discussion}

The values of track width measured for enamel were considerably higher than the values predicted by the Hertzian analysis. These high values are interpreted to reflect the apparent ductility of enamel under conditions of sliding at loads a factor of 10 to 100 times higher than those used for fluorapatite in water. The high values of $\beta$ reflect the contribution of plowing friction that resulted from this ductility. The ductility in

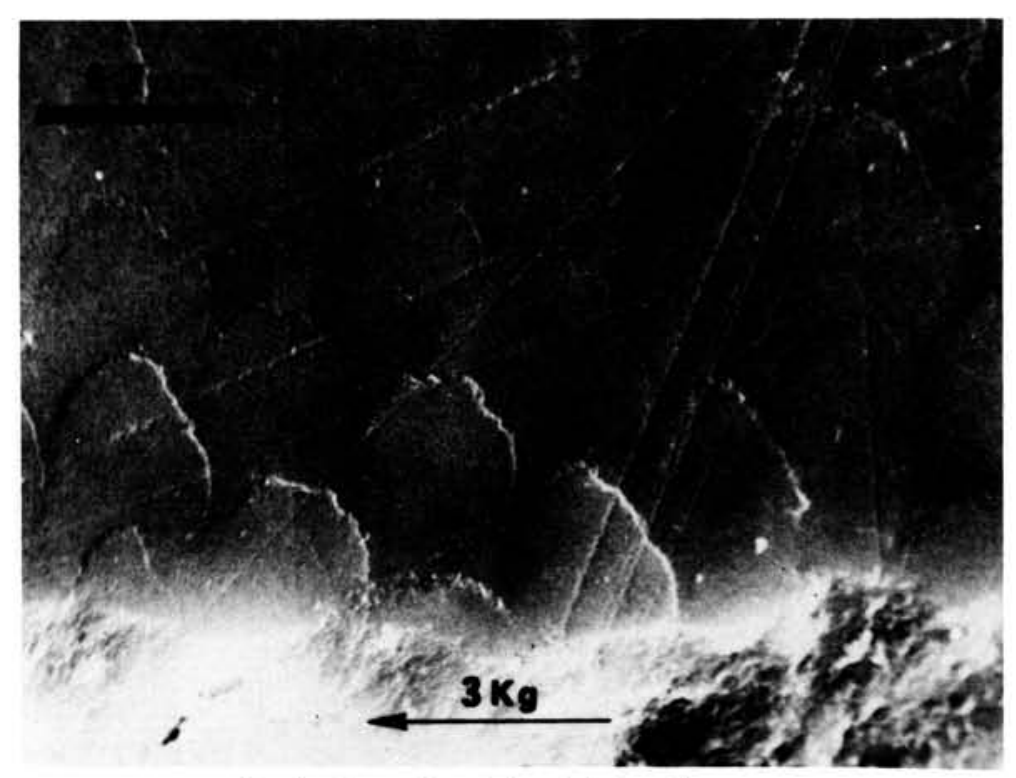

Fig 6.-Enamel rods in vicinity of wear scar. 
the center of the track of enamel persisted to loads of $3 \mathrm{~kg}$, at which point the slider broke through the relatively thin enamel layer into dentin. The influence of the thickness of the enamel layer in its effect on mechanical behavior was not considered in this study. At loads greater than $500 \mathrm{gm}$ intermittent cracking occurred. It appeared that cracks propagated around the enamel rods and through the proteinaceous material that binds the enamel rods together. Enamel apparently behaves as a composite material.

The surface failure of enamel under sliding may be influenced to a considerable degree by the size of the indenter (relative to the size of the enamel rods) used for sliding. A large diameter slider such as that used in the present study may distribute its load among a number of rods, which results in the observed ductility. A smaller diameter slider with a radius of less than 2 micrometers $(\mu \mathrm{m})$, however, might be expected to concentrate stress at a given time on only one rod. Under this condition, surface failure could be quite different.

Frazier $^{3}$ has observed that all enamel samples collected by grinding with high- or lowspeed diamond stones or by carbide burs contained large amounts of finely divided enamel, a relatively large number of scattered individual crystals, and relatively few particles (usually less than $5 \mu \mathrm{m}$ in size). Prolonged ball grinding produced a significant amount of finely divided material $(<0.025$ $\mu \mathrm{m})$; the amount increased with increased grinding. Under conditions of grinding by dental burs or by ball grinding, line broadening in X-ray diffraction measurements was observed for human enamel, but not for a specimen of synthetic hydroxyapatite. ${ }^{2}$

In this study, the amount of broadening caused by dental burs depended on one or more of the following factors: coarseness of cutting instrument, grinding speed, grinding direction, and the presence or absence of water. These observations are consistent with a theory that to observe brittle failure of enamel, perhaps of the type observed for fluorapatite, ${ }^{4}$ slider dimensions in the order of or less than the average size of the enamel rods are required. Such a criterion normally would be met by grinding with dental burs or stones and abrasion by hard particles. The possibility of observing a ductile-to-brittle transition for enamel under sliding is good, because Wright ${ }^{1}$ has suggested that human dental tissue might exhibit a ductile behavior for indentations of about $0.5 \mu \mathrm{m}$.

The propagation of cracks observed along the Hunter-Schreger bands suggests that under suitable conditions, strain may be accommodated in enamel by the propagation of cracks along natural defects present in the enamel and dentin.

\section{Conclusions}

The frictional behavior and surface failure of human enamel were evaluated under sliding in water. At loads of up to $1 \mathrm{~kg}$, ductility in the center of the track was apparent. The measured track widths and the values of $\beta$ were consistent with a large component of plowing friction. Intermittent cracks were observed that appeared to propagate around the enamel rods and to follow natural flaws in the enamel and dentin.

\section{References}

I. Wricht, K.H.R.: The Abrasive Wear Resistance of Human Dental Tissues, Wear 14: 263-284, 1969.

2. Frazier, P.D., and Coltuet, C.V.: Adult Human Enamel I. Influence of Grinding upon X-ray Diffraction Profile Breadth, Calc Tiss Res 3: 308-317, 1969.

3. Frazier, P.D.: Adult Human Enamel II. An Electron Microscope Study of the Effect of Grinding, Calc Tiss Res 5: 277-287, 1970.

4. Powers, J.M.: The Influence of Crystallographic Direction and Environment on the Ductile to Brittle Transition of Fluorapatite Single Crystals under Sliding, PhD dissertation, University of Michigan, 1972.

5. LUdemA, K.C.: An Investigation of the Use of the Incident-Light Phase Contrast Microscope in the Observation of Asperities on Metal Surfaces, PhD dissertation, University of Michigan, 1962.

6. Craig, R.g.; Peyton, F.A.; and Johnson, D.W.: Compressive Properties of Enamel, Dental Cements, and Gold, $J$ Dent Res 40: 936-945, 1961.

7. Katz, J.L., and Ukraincik, K.: On the Anisotropic Elastic Properties of Hydroxyapatite, J Biomechanics 4: 221-227, 1971. 